Regarding pregnancy complications and outcomes, no cases of Preeclampsia, eclampsia, small for gestational age babies, intrauterine death, were observed. One pregnancy was complicated with pre-term premature rupture of membranes at 35 gestational week, in a patient not taking prednisone. There were $5(25 \%)$ pre-term deliveries.

Conclusion: Nearly one third of pregnant patients with JIA had a disease flare during pregnancy. Flares were observed only in 2 disease subsets (PLA; OLA-E) and associated with discontinuation of bDMARDs at positive pregnancy index. The preconception counseling of patients with JIA should include the disease subset in the risk stratification and consequently the continuation of bDMARDs during pregnancy. Maternal disease control is necessary to minimize the risk of adverse pregnancy outcomes (especially pre-term birth).

Disclosure of Interests: Antía García Fernández: None declared, Laura Andreoli: None declared, Maria Chiara Gerardi: None declared, Francesca Crisafulli: None declared, Cecilia Nalli: None declared, Matteo Filippini: None declared, Roberto Gorla: None declared, Marco Taglietti: None declared, Micaela Fredi: None declared, Maria Grazia Lazzaroni: None declared, Andrea Lojacono: None declared, Sonia Zatti: None declared, Franco Franceschini: None declared, Angela Tincani Consultant for: UCB, Pfizer, Abbvie, BMS, Sanofi, Roche, GSK, AlphaSigma, Lilly, Jannsen, Cellgene, Novartis

DOI: 10.1136/annrheumdis-2019-eular.6891

\section{THU0520 EARLY IDENTIFICATION OF VENTRICULAR DYSFUNCTION IN JUVENILE SYSTEMIC SCLEROSIS BY SPECKLE TRACKING ECHOCARDIOGRAPHY}

Giovanni Civieri ${ }^{1}$, Biagio Castaldi ${ }^{2}$, Giorgia Martini $^{1}$, Ornella Milanesi ${ }^{2}$, Francesco Zulian'. 'Pediatric Rheumatology, Department of Woman's and Child's Health, University of Padova, Padova, Italy, ${ }^{2}$ Pediatric Cardiology, Department of Woman's and Child's Health, University of Padova, Padova, Italy

Background: Juvenile Systemic Sclerosis (JSSc) is a rare multisystemic connective tissue disease, with onset before the age of 16. Cardiac involvement, recognized in $8-24 \%$ of the patients [1], begins in early stages of JSSc and has a poor prognosis. The traditional cardiac US imaging, including the left ventricular ejection fraction (EF), evaluates the global function of the heart, thus being inappropriate to assess the subclinical course of the disease. A new echocardiographic technique, the speckle tracking echocardiography (STE), has been shown to be able to identify regional ventricular dysfunctions also in early stages of adult-onset $\mathrm{SSc}[2,3]$.

Objectives: Aim of our study was to assess the longitudinal strain of right and left ventricle in JSSc patients, in order to identify ventricular dysfunctions earlier and more effectively than with traditional echocardiography. Furthermore, we investigated the evolution of cardiac involvement during the follow-up and possible correlations with the overall disease severity, measured by the Juvenile Systemic Sclerosis Severity Score (J4S)[4].

Methods: Consecutive patients with JSSc underwent clinical and cardiologic evaluation. This included traditional echocardiography (such as $\mathrm{M}$ Mode, EF, Pulsed- and Tissue-Doppler), 3D-Echocardiography and STE, measuring the global longitudinal strain of left ventricle (GLS) and the longitudinal strain of right ventricle free-wall (RVLS). Each patient was assessed several times by pediatric rheumatologists for J4S and by cardiologists with STE and standard echo.

Results: $18 \mathrm{JSSc}$ patients (12 F, $6 \mathrm{M})$, mean age 12.3 years, disease duration 4.5 years, entered the study. At baseline evaluation, EF was abnormal in 1 patient, whereas GLS and RVLS were abnormal in 5 . The diagnostic sensitivity of cardiac involvement of STE increased, with a prevalence rising from $22.2 \%$ to $38.8 \%$. During the follow-up, lasted mean 30 months (range 17-43), the mean GLS values gradually worsened $(-21.2 ;-20.1 ;-19.4 \%)$ while there was no significant variations of EF. The strong correlation between GLS and J4S, found at baseline, vanished during the follow-up.

Conclusion: Speckle tracking echocardiography is a useful technique to evaluate the cardiac involvement in patients with JSSc. In comparison with traditional EKG or echocardiography, it allows to increase the diagnostic sensitivity of cardiac involvement. Over time, we observed a gradual worsening of GLS, sign of a progressive left ventricular dysfunction, that was not identified by EF. It is possible that the coronary microvascular damage compromises the subendocardial fibers function which are more sensitive to ischemia and whose contractility is well assessed by GLS [5]. Finally, the initial correlation between strain and J4S disappeared during the follow-up, maybe because of the pharmacological therapy, which was effective on several aspects of the disease but had low impact on the ventricular function.

\section{REFERENCES:}

[1] Martini G et al. Arthritis Rheum 2006; 54:3971-3978.

[2] Spethmann S et al. Eur. Heart J Cardiovascular Imaging 2012; 13:863870.

[3] Dedeoglu R et al. Pediatric Cardiol 2017; 38:1686-1695.

[4] La Torre F et al. Arthritis Rheum 2012; 64:4143-4150.

[5] Geyer H et al. J Am Soc Echocardiog 2010; 23:351- 369.

Disclosure of Interests: None declared

DOI: 10.1136/annrheumdis-2019-eular.6678

\section{THU0521 JUVENILE DERMATOMYOSITIS IN GERMANY - DATA OF THE NATIONAL PEDIATRIC RHEUMATOLOGY DATABASE WITH SPECIAL REGARD TO MYOSITIS- SPECIFIC ANTIBODIES AND ASSOCIATED CLINICAL PHENOTYPES}

Claudia Sengler ${ }^{1}$, Svea Horn ${ }^{1}$, Nadine Grösch ${ }^{1}$, Jens Klotsche ${ }^{1}$,

Martina Niewerth ${ }^{1}$, Fabian Speth ${ }^{2}$, Peter Haas ${ }^{3}$, Claas Hinze ${ }^{4}$, Gerd Horneff ${ }^{5}$ Tilmann Kallinich $^{6}$, Frank Weller-Heinemann ${ }^{7}$, Nadine Unterwalder ${ }^{8}$,

Kirsten Minden ${ }^{1} .{ }^{1}$ German Rheumatism Research Center, Berlin, Germany; ${ }^{2}$ University of Rostock, Rostock, Germany, ${ }^{3}$ German Center for Pediatric and Adolescent Rheumatology, Garmisch-Partenkirchen, Germany; ${ }^{4}$ University of Münster, Department of Pediatric Rheumatology and Immunology, Münster, Germany, ${ }^{5}$ Center for General Pediatrics and Neonatology, Asklepios Klinik, Sankt Augustin, Germany; ${ }^{6}$ Charité - Universitätsmedizin Berlin, Department of Pediatric, Division of Pneumonology and Immunology, Berlin, Germany; ${ }^{7}$ Prof.-Hess-

Kinderklinik, Berlin, Germany; ${ }^{8}$ Labor Berlin, Berlin, Germany

Background: Next to weakness of the proximal muscles and typical skin lesions as leading symptoms in juvenile dermatomyositis (JDM) there can be involvement of other organ systems and tissues. Myositis-specific antibodies (MSA) may help to distinguish clinically distinct phenotypes

Objectives: 1) to analyse the clinical presentation of JDM and how diagnosis was verified and 2) to determine the spectrum of MSA and the associated clinical phenotypes in a German cohort of JDM patients.

Methods: We analyzed data of the national pediatric rheumatology database (NPRD), where children and adolescents with chronic rheumatic diseases are documented yearly by means of disease-specific questionnaires. Cross-sectional data of patients with JDM documented between 2014 and 2016 were analyzed. MSA were determined by a commercial multiplex array. To further specify the phenotype and patient's outcome, an additional retrospective chart review was conducted.

Results: We identified 186 patients with a diagnosis of JDM (69\% female). Mean age at disease onset was $6.8 \pm 3.5$ years, mean time between first symptoms and first contact to a pediatric rheumatologist was $6.1 \pm 8.9$ months, mean age at documentation was $11.5 \pm 4.4$ years. The following diagnostic procedures were pathologic/positive for JDM: Histology 44/147 (30\%), electromyography 28/144 (19\%), magnetic resonance imaging $103 / 148(70 \%)$, Creatine kinase (CK) elevation at diagnosis $126 / 148$ patients $(85 \%)$. At last consultation (mean disease duration $5.0 \pm 3.9$ years), the mean physician`s global assessment of disease activity (PGA, NRS $0-10$ ) was $1.6 \pm S D 2.3$, the mean manual muscle test (MMT, range $0-80$, best 80 ) was $69.7 \pm S D 19$, the mean disease activity score (DAS, range $0-20$, best 0 ) was $4.4 \pm D$ 4.7, the mean $\mathrm{CHAQ}$ was $0.5 \pm \mathrm{SD} 0.8$. MSA testing was performed on 88 patients $(73 \%$ female); $42 \%$ tested positive: anti-NXP2 $16 \%$, anti-TIF1 $\gamma$ $14 \%$, anti-MDA5 6\%, anti-Mi2 3\%, anti-synthetase-antibodies $3 \%$. The most common clinical feature was dysphagia in patients with anti-NXP2, calcinosis in patients with anti-TIF1 $\gamma$, lung involvement in patients with anti-synthetase antibodies, and pronounced muscle weakness in patients with anti-Mi2. Patients with anti-MDA5 were characterized by frequent lung involvement, mucosal ulcers, fever and polyarticular arthritis of small joints. Muscle weakness tested by Childhood Myositis Assessment Score (CMAS) was significantly associated with an increased CK level. At last consultation, $32 \%$ and $14 \%$ received oral glucocorticoids (GC) $<0.2 \mathrm{mg} /$ $\mathrm{kg}$ or $\geq 0.2 \mathrm{mg} / \mathrm{kg}$ body weight, respectively, $52 \%$ were treated with methotrexate (MTX) and $27 \%$ with intravenous immunoglobulins (last 12 months). PGA was $\leq 1$ in $65 \%$ of patients at last consultation, $22 \%$ of those were off therapy.

Conclusion: Demographic and clinical parameters of patients with JDM in Germany are comparable to JDM-cohorts in other countries. MRI has gained diagnostic importance and is used more than twice as often as biopsy. MSA could be found in almost half of the patients. Clinical 
phenotypes were associated with specific MSA. After 5 years, 2/3 of patients had an inactive disease, but about half of all patients still received MTX and GC therapy.

Disclosure of Interests: Claudia Sengler: None declared, Svea Horn: None declared, Nadine Grösch: None declared, Jens Klotsche: None declared, Martina Niewerth: None declared, Fabian Speth: None declared, Peter Haas Grant/research support from: Pfizer, Claas Hinze: None declared, Gerd Horneff: None declared, Tilmann Kallinich Grant/research support from: Novartis, Speakers bureau: Sobi, Roche, Novartis, CLB, Frank Weller-Heinemann: None declared, Nadine Unterwalder: None declared, Kirsten Minden Consultant for: AbbVie DOI: 10.1136/annrheumdis-2019-eular.3253

\section{THU0522 CLINICAL MANIFESTATIONS AND COMPARISON OF SUBTYPES OF JUVENILE IDIOPATHIC INFLAMMATORY MYOPATHIES: DATA FROM THE REMICAM REGISTRY}

Jesús Loarce-Martos ${ }^{1}$, Carmen Larena ${ }^{1}$, M. Ángeles Blázquez ${ }^{1}$, Beatriz JovenIbáñez ${ }^{2}$, Patricia Carreira ${ }^{2}$, Francisco J López-Longo ${ }^{3}$, Julia Martinez-Barrio ${ }^{3}$, J. C. López Robledillo ${ }^{4}$, Raquel Almodovar ${ }^{5}$, María Jesús García de Yébenes ${ }^{6}$, Laura Nuño ${ }^{7}$, REMICAM. ${ }^{1}$ HU Ramón y Cajal, Madrid, Spain, ${ }^{2} \mathrm{HU} 12$ de Octubre, Madrid, Spain; ${ }^{3} \mathrm{HU}$ Gregorio Marañón, Madrid, Spain; ${ }^{4} \mathrm{HU}$ Niño Jesús, Madrid, Spain; ${ }^{5} \mathrm{HU}$ Fundación Alcorcón, Madrid, Spain; ${ }^{6}$ Instituto Salud Musculoesquelética Inmusc, Madrid, Spain; ${ }^{7} \mathrm{HU}$ La Paz, Madrid, Spain

Background: Juvenile idiopathic inflammatory myopathies (JIIM) are a heterogeneous group of autoimmune diseases affecting children, characterized by symmetric muscular weakness, cutaneous rash and systemic organ involvement. Given its low incidence, there are few studies describing the characteristics of this disease and its subtypes in Spanish patients ${ }^{1}$.

Objectives: To describe the demographic, clinical and analytical characteristics of patients with JIIM from the registry of inflammatory myopathies in Madrid community (REMICAM), and to compare those measures between polymyositis (PM) and juvenile dermatomyositis (JDM) subgroups. Methods: A multicentre retrospective study from the REMICAM registry was performed. Patients were selected if they were 18 years or younger at onset of JIIM and met definite or probable criteria for IIM by the modified Bohan and Peter criteria. We included patients with JDM or PM subgroups, overlap myositis patients were excluded.

Results: 86 patients were included, 12 classified as PM and 74 as JDM. $70 \%$ were women and $96 \%$ were Caucasian. Mean age at diagnosis was 11.8 years in PM group vs 7.2 years in JDM group. 44\% presented arthritis and $93 \%$ presented muscular weakness. Gottron sign was present in $76 \%$ of the patients, and calcinosis was present in $31.4 \%$. Cardiac and pulmonary manifestations were rare $(<5 \%)$. There were no cases of neoplastic disease. Clinical features and complementary analysis are shown in table 1 and table 2 .

Abstract THU0522 -Table 1. Clinical features

\begin{tabular}{lcccc}
\hline & $\begin{array}{c}\text { Total } \\
(\mathbf{n}=86)\end{array}$ & $\begin{array}{c}\text { PM } \\
(\mathbf{n}=12)\end{array}$ & $\begin{array}{c}\text { JDM } \\
(\mathbf{n}=74)\end{array}$ & p-value \\
\hline Fever & $23(29,1 \%)$ & $6(50,0 \%)$ & $17(25,4 \%)$ & 0,084 \\
Weight loss & $12(15,2 \%)$ & $1(8,3 \%)$ & $11(16,4 \%)$ & 0,680 \\
Arthralgia & $38(44,2 \%)$ & $7(58,3 \%)$ & $31(41,9 \%)$ & 0,287 \\
Arthritis & $24(28,4 \%)$ & $6(50 \%)$ & $18(24,7 \%)$ & 0,071 \\
Gottron sign & $66(76,7 \%)$ & & $65(87,8 \%)$ & \\
Heliotrope erythema & $46(53,5 \%)$ & & $46(62,2 \%)$ & \\
Mechanic hands & $10(12,3 \%)$ & & $10(14,5 \%)$ & \\
Skin ulcers & $3(3,7 \%)$ & & $3(4,3 \%)$ & \\
Raynaud & $12(13,9 \%)$ & $3(25,0 \%)$ & $9(12,2 \%)$ & 0,362 \\
Calcinosis & $27(31,4 \%)$ & $2(16,7 \%$ & $25(33,8 \%)$ & 0,325 \\
Muscular weakness & $80(93,0 \%)$ & $11(91,7 \%)$ & $69(93,2 \%)$ & 1,000 \\
Myalgia & $68(83,9 \%)$ & $8(66,7 \%)$ & $60(87,0 \%)$ & 0,095 \\
Myocarditis & $2(2,3 \%)$ & & $2(2,7 \%)$ & \\
Arrythmia & $3(3,5 \%)$ & $1(8,3 \%)$ & $2(2,7 \%)$ & 0,370 \\
Heart failure & $1(1,2 \%)$ & & $1(1,4 \%)$ & 1,000 \\
Interstitial lung disease & $1(1,2 \%)$ & $1(8,3 \%)$ & & 0,140 \\
Dysphagia & $19(22,1 \%)$ & $2(16,7 \%)$ & $17(23,0 \%)$ & 1,000 \\
GI reflux & $7(8,1 \%)$ & $1(8,3 \%)$ & $6(8,1 \%)$ & 1,000 \\
Gl hemorrhage & $1(1,2 \%)$ & & $1(1,3 \%)$ & 1,000 \\
\hline
\end{tabular}

Abstract THU052 -Table 2. Complementary test.

\begin{tabular}{lcccc}
\hline & $\begin{array}{c}\text { Total } \\
(\mathbf{n}=\mathbf{8 6})\end{array}$ & $\begin{array}{c}\text { PM } \\
(\mathbf{n = 1 2})\end{array}$ & $\begin{array}{c}\text { JDM } \\
(\mathbf{n}=\mathbf{7 4})\end{array}$ & $\begin{array}{c}\mathbf{p}- \\
\text { value }\end{array}$ \\
\hline Anemia & $13(15,1 \%)$ & $4(33,3 \%)$ & $9(12,2 \%)$ & 0,079 \\
Leukopenia & $4(4,6 \%)$ & $1(8,3 \%)$ & $3(4,0 \%)$ & 0,458 \\
Thrombocytopenia & $3(3,5 \%)$ & $2(16,7 \%)$ & $1(1,3 \%)$ & 0,050 \\
ANA+ & $34(40,5 \%)$ & $7(58,3 \%)$ & $27(37,5 \%)$ & 0,173 \\
Anti-Jo1 & $2(2,6 \%)$ & & $2(3,0 \%)$ & 1,000 \\
CPK & $431(97-$ & $206(36-$ & $659(104-$ & 0,730 \\
& $3131)$ & $7428)$ & $3110)$ & \\
Aldolase & $12(9-18)$ & $9(5-12)$ & $12(9-19)$ & 0,230 \\
CRP & $0,35(0-1,3)$ & $0,12(0-2,8)$ & $0,42(0-1,3)$ & 0,817 \\
ESR & $19(11-29)$ & $25(13-42)$ & $19(11-29)$ & 0,450 \\
Myopathic pattern & $72(92,3 \%)$ & $12(100 \%)$ & $60(90,1 \%)$ & 0,508 \\
\hline
\end{tabular}

Conclusion: JDM was the most frequent form of MIIJ in our study $(86 \%)$. The most frequent manifestations were the muscular and dermatological ones, but an important group also presented arthritis and fever. There was no statistical difference between both groups, regardless, myalgias and dysphagia were more common in JDM group, and they had higher CPK and aldolase values. PM patients were older, had more fever and arthritis, also, cytopenia and ANA positivity were more common.

\section{REFERENCE:}

[1] Shah M, Mamyrova G, Targoff IN, Huber AM, Malley JD, Rice MM, et al. The Clinical Phenotypes of the Juvenile Idiopathic Inflammatory Myopathies. Medicine (Baltimore). 2013 Jan;92(1):25-41.

Disclosure of Interests: Jesús Loarce-Martos: None declared, Carmen Larena: None declared, M. Ángeles Blázquez: None declared, Beatriz JovenIbáñez Speakers bureau: Celgene, Novartis, MSD, Pfizer, AbbVie, and Janssen, Patricia Carreira: None declared, Francisco J López-Longo: None declared, Julia Martinez-Barrio: None declared, J.C. López Robledillo: None declared, RAQUEL ALMODOVAR: None declared, María Jesús García de Yébenes: None declared, Laura Nuño: None declared DOI: 10.1136/annrheumdis-2019-eular.4947

\section{THU0523 OBESITY IS ASSOCIATED WITH SEVERE RENAL INVOLVEMENT, PERSISTENT PURPURA AND LONGER JOINT SYMPTOMS IN CHILDREN WITH HENOCH SHÖNLEIN PURPURA}

$\underline{\text { Hatice Adiguzel Dundar }}^{1,1}$, Mehmet Pektanc $^{2}$, Meral Torun Bayram ${ }^{3}$, Alper Soylu $^{4}$, Salih Kavukcu $4^{4}{ }^{1}$ Dokuz Eylul University Faculty of Medicine, Department of Pediatrics, Pediatric Rheumatology Unit, izmir, Turkey; ${ }^{2}$ Dokuz Eylul University Faculty of Medicine, Department of Pediatrics, izmir, Turkey; ${ }^{3}$ Dokuz Eylul University Faculty of Medicine, Department of Pediatrics, Pediatric Nephrology Unit, izmir, Turkey; ${ }^{4}$ Dokuz Eylul University Faculty of Medicine, Department of Pediatrics, Pediatric Nephrology and Rheumatology Unit, izmir, Turkey

Background: Over the last 20 years, the prevalence of obesity is increased in the developed and developing countries. Adipose tissue has an effect on inflammatory processes and immune system besides metabolic and appetite regulating mechanisms. On this basis, it is now of major interest to clarify the relationship between obesity and autoimmune/ inflammatory diseases $(1,2)$.

Objectives: We aimed to evaluate the role of obesity on the clinical course and response to treatment in patients with Henoch Shönlein Purpura (HSP).

Methods: Data charts of children with HSP followed in Dokuz Eylül University Childrens' Hospital were reviewed retrospectively. Obesity was defined as BMI $\geq 95$ percentile in conformity with Centers for Disease Control and Prevention (CDC) (3). Persistant purpura was defined as skin involvement persisting for $\geq 30$ days. Mild nephropathy was defined by the presence of microscopical hematuria and/or nonnephrotic proteinuria, and severe nephropathy by nephrotic syndrome and/or acute nephritic syndrome and/or renal insufficiency (4). Patients were grouped as obese and non-obese depending on BMI. Two groups were compared for demographic, clinical and laboratory parameters.

Results: There were 199 patients [M/F:104/95; presenting age 7.1 years (range 5.0-9.2); follow-up period 17.5 months (range 3-50)]. Obesity was 